\title{
College Students' Consciousness of Participation in Leisure Activities Behavior Related Research
}

\author{
Jianqiang Guo, Xian Liu* \\ Chang Zhou University School of Physical Education, Chang Zhou, Jiangsu, China. \\ * Corresponding author. Tel.: 13861171556; email: lx@cczu.edu.cn \\ Manuscript submitted June 2, 2016; accepted August 12, 2016. \\ doi: 10.17706/ijeeee.2016.6.3.186-192
}

\begin{abstract}
In this paper, through the survey method, this study is to investigate the behavioral intention model of students participating in leisure sports in colleges and universities, with the purposes of analyzing students' behavioral intention to participate in leisure sports, constructing the structural equation for factors such as behavioral intention, attitude, subjective norm and perceived behavior control, understanding quantitatively the reasons to participate leisure sports, discussing the influences and hierarchies of the factors, and figuring out the causal relationship. We expect the results of this current study can be an elaboration of behavioral intentions of students participating in leisure sports, a basis for increasing the frequency of such participation, as well as a reference for schools to plan and improve their leisure sports. We also expect more scholars will pay attention to the physical exercise in colleges and universities and put forward some good strategies.
\end{abstract}

Key words: Leisure activities, behavior related, college students'.

\section{Introduction}

The 21st century is the beginning of human walk highly civilized society. With the continuous improvement of the social productive forces and the transformation of the social relations of production, it is basically out of the heavy burden and the shackles of the physical labor, and then began to chase the improvement of the quality of life of the spiritual dimension, leisure into every corner of people's lives. Social progress for people with plenty of free time and economic conditions to participate in recreational sports activities, to enjoy leisure psychological satisfaction and happiness[1]. A popular leisure times toward us, a universal participation in leisure activities amazing picture will be displayed in front of us in the near future.

As the leading force of China's educational undertakings reserve talents of the Normal University students, groups have advanced knowledge can't be ignored as a society today, the leisure sports consciousness, strength, and leisure sports activities good or bad, will directly affect the college The students would be able to grasp the comprehensive subject knowledge and have a healthy physical and mental conditions, will have a far-reaching impact on the development of China's socialist educational undertakings[2].

\section{Hypothetical Model of Behavioral Intention of College Student Participating in Leisure Sports}

Attitude of a college student on leisure sports will influence his/her behavioral intention to participate 
in leisure sports, and is the factor that has the highest influence on behavioral intention. This implies that if a college student can have a positive attitude on leisure sports, his/her behavioral intention to participate in leisure sports can thus be enhanced [3]. Therefore, when an administrative department plans to promote students' participation in leisure sports, it shall let students feel that sports are beneficial, pleasant and meaningful, so as to enhance their behavioral intention to participate in leisure sports. Subjective norm of a college student also has effective influence on his/her behavioral intention to participate in leisure sports, and is the factor that has the second highest influence on behavioral intention. This means that a more positive subjective norm in the mind of a college student can lead to a stronger behavioral intention to participate in leisure sports. When popularizing leisure sports for students in colleges and universities, therefore, the influence of important reference groups can be utilized to strengthen students' behavioral intention. Families, neighbors or friends can also be influenced when the concept of participating in sports is taken to home. As a result, more people will be motivated to participate in leisure sports. The factor of perceived behavior control on leisure sports also shows a significant and positive influence on behavioral intention[4]. This suggests that if a college student has stronger ability of the perceived behavior control, he/she then has stronger behavioral intention to participate in leisure sports. Hence, communities and schools shall build more convenient sport facilities and strengthen sport publicity so that students can have more chances to participate in sports. Meanwhile, they shall get rid of various obstacles to improve students' ability to control behaviors, as shown below in fig 1:

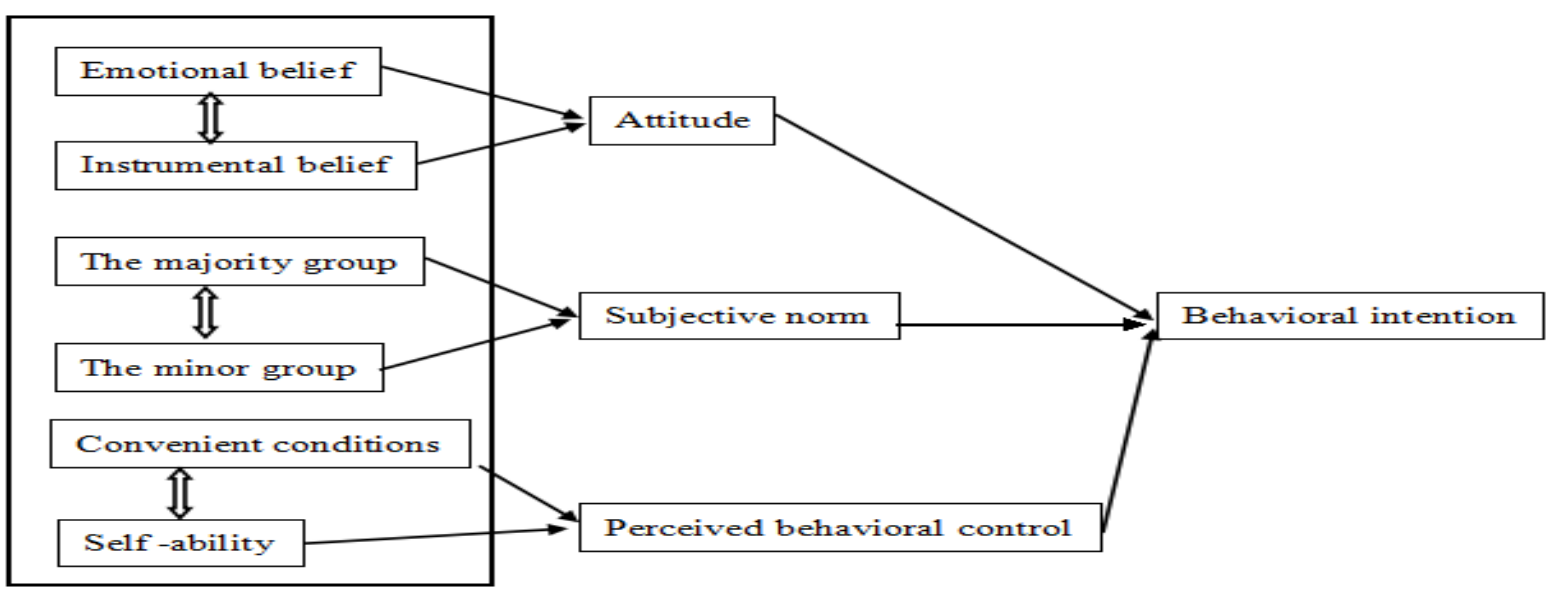

Fig. 1. students' ability of behavioral intention.

To know and study the tendency of a high college to choose leisure sports, it must cover all factors that have influence on his/her participation in leisure sports. For this reason, the study shall cover both subjective and objective factors, of which the former includes sport interests \& hobbies and sport attitudes \& habits, while the later includes sport atmosphere in schools, social influences and sport fields[5]. As long as the University Physical Education Department can improve the degree of attention to leisure education and develop the school and the surrounding resources positively, we will be able to find the effective breakthrough point of leisure sports education.

\subsection{College Students' Sport Interests and Hobbies}

Motivation of a student to participate in sports comes mainly from his/her interest in sport activities, and the key is the emotional experience of the individual in his/her active participation. In other words, it is whether the individual can fully experience the enjoyment from sports, whether he/she has a pleasant emotional experience or satisfaction, and whether he/she has a desire to participate the sports again [6].

According to the investigation listed in Table 1 we see that students have different motivations to 
participate in leisure sports. By sorting out the investigation results we find that the first motivation is physical fitness: 114 out of the 225 students had selected this item, accounting for $50.7 \%$, followed by recreation \& amusement, emotion adjustment \& stress relieve, enrichment of extracurricular life, etc., which indicates that college students have better cognition on leisure sports. Physical education (PE) is not only a foundation course but also an important part of life [7]. In difference between boys and girls, boys like toned body more while girls prefer enjoyment and body shaping when doing physical exercises. This is associated with the difference of psychophysical characteristics between male and female. The first three motivations of college students to participate in leisure sports are enrichment of extracurricular life, body shaping and physical health. For boys, the top motivations are enrichment of extracurricular life, body shaping and physical health, while for girls, the top motivations are body shaping, enrichment of extracurricular life and physical health, respectively. So when the college PE teachers choose leisure sports education content, they should not only fully respect the objective law of sports and physical and mental development of students, but also should absorb the new result of the leisure sports in theory and practice, demonstrate the construction of leisure sports content age feature, correctly handle therelationship between choosing course content and the regional characteristic construction, emphasis and broaden the curriculum content, the content of education theory and practice education experience so that it can make leisure sports education better meet the realistic need of the leisure sports education content system. In short, the leisure sports education theory should include the basic principle leisure, leisure sports ,leisure culture, leisure philosophy and other aspects.

Table 1. Statistics of Motivations of Participating in Leisure Sports

\begin{tabular}{|c|c|c|c|c|c|c|}
\hline Type of motivation & $\begin{array}{c}\text { Boys } \\
(\%)\end{array}$ & Rank & $\begin{array}{c}\text { Girls } \\
(\%)\end{array}$ & Rank & $\begin{array}{c}\text { In total } \\
(\%)\end{array}$ & Rank \\
\hline Physical fitness & 65 & 1 & 34.2 & 4 & 50.7 & 1 \\
\hline Strengthen interpersonal skills & 40 & 4 & 11.4 & 6 & 26.7 & 5 \\
\hline Improve technical skills & 22.5 & 6 & 8.5 & 7 & 16 & 7 \\
\hline Recreation \& amusement & 45 & 3 & 45.7 & 1 & 45.3 & 2 \\
\hline Emotion adjustment \& stress relieve & 47.5 & 2 & 31.4 & 5 & 40 & 3 \\
\hline Personality development & 15 & 7 & 0 & 8 & 8 & 8 \\
\hline Body shaping & 5 & 8 & 42.9 & 2 & 22.7 & 6 \\
\hline Enrichment of extracurricular life & 30 & 5 & 37.1 & 3 & 33.3 & 4 \\
\hline
\end{tabular}

\subsection{College Students' Attitudes and Habits for Participating in Leisure Sports}

View of sports value is a view and tendency that dominates people's sport behaviors, and is also people's assessment of the good and the bad, the right and the wrong, and the importance of sport behaviors. It is a mental strength governing our sport behaviors, and is a form of recognizing things. Though the saying "attitude is everything" is a little bit too subjective, a right attitude on leisure sports can have great influence on participation. Behavior is a natural form of habit [8].

Table 2. Statistics of Times and Attitudes of Participating in Leisure Sports Per Week

\begin{tabular}{|c|c|c|c|c|c|c|c|c|c|}
\hline & $\begin{array}{c}0 \\
\text { times }\end{array}$ & $\begin{array}{c}1-2 \\
\text { times }\end{array}$ & $\begin{array}{c}3-4 \\
\text { times }\end{array}$ & $\begin{array}{c}5-6 \\
\text { times }\end{array}$ & $\begin{array}{c}\text { Above 6 } \\
\text { times }\end{array}$ & $\mathrm{A}$ & $\mathrm{B}$ & $\mathrm{C}$ & $\mathrm{D}$ \\
\hline $\begin{array}{c}\text { Number } \\
\text { of boys }\end{array}$ & 3 & 54 & 48 & 12 & 3 & 90 & 21 & 6 & 3 \\
\hline$\%$ & 2.5 & 45.5 & 40 & 10 & 2.5 & 75 & 17.5 & 5 & 2.5 \\
\hline $\begin{array}{c}\text { Number } \\
\text { of girls }\end{array}$ & 6 & 45 & 39 & 9 & 0 & 57 & 27 & 15 & 6 \\
\hline$\%$ & 5.7 & 42.9 & 37.1 & 8.6 & 0 & 54.3 & 25.7 & 14.3 & 5.7 \\
\hline In total & 9 & 99 & 87 & 21 & 3 & 147 & 48 & 21 & 9 \\
\hline$\%$ & 4 & 44 & 38.7 & 9.3 & 1.3 & 65.3 & 21.3 & 9.3 & 4 \\
\hline
\end{tabular}

(A-very interested; B-relatively interested; C-careless; D-not interested) 
As indicated in the investigation, there are only $38.7 \%$ of the college students who take exercises three to four times every week, among which, boys accounting for $40 \%$, higher than $37.1 \%$ accounted by girls. The proportion of the college students who take exercises one to two times per week is 44\%; likewise, the proportion of boys is higher than that of girls. In the investigation there are several students who take even no exercises in a week. In general, however, the proportion of college students who take exercises three times or more each week has reached to $50 \%$, indicating the increase of the times of taking physical exercises. The proportion of boys who are "very interested" or "relatively interested" in leisure sports is $90 \%$, and the proportion of girls is also close to $80 \%$, with an average of $87 \%$ at the whole level, as shown in Table 2. Objective Factors That Have Influence on College Students' Participation in Leisure sports influence of sport atmosphere on selection of leisure sports

A: The degree that schools pay attention to sports as well as the way of management

B: Sports teaching and training

C: The attitude towards sports activities and organizing ability of class teachers and counselors

D: The high level sports team of college

Sport atmosphere in a college or university has a certain influence on students' participation in leisure sports. As can be known from Fig. 2, in all the four sport atmospheres, ordinary students are mainly influenced by physical education (PE)62.4\%, extracurricular training and high-level sport teams, while the school's emphasis, its management style $58.3 \%$, teachers and instructors have much less influence $19.6 \%$. Perhaps this is related to the high independence of college students and may be because almost no sport activities are organized by teachers and instructors, except large-scale games. Interestingly, a good result by a high-level sport team has great influence on ordinary students of the school. Only by helping to establish the correct concept of leisure, leisure, can we promote the healthy, comprehensive development and the progress of the whole society. Based on leisure sports filled with open, fitness and entertainment in college physical education, promoting the leisure sports education actively has become an inevitable reform of physical education in Colleges and universities. Leisure sports taking the advantage of school education intermediary, can be better to teach the value of leisure sports and leisure education concept, through effective measures, help the students deepen the understanding of leisure sports, enhance students' physique and improve the quality of life education goal.

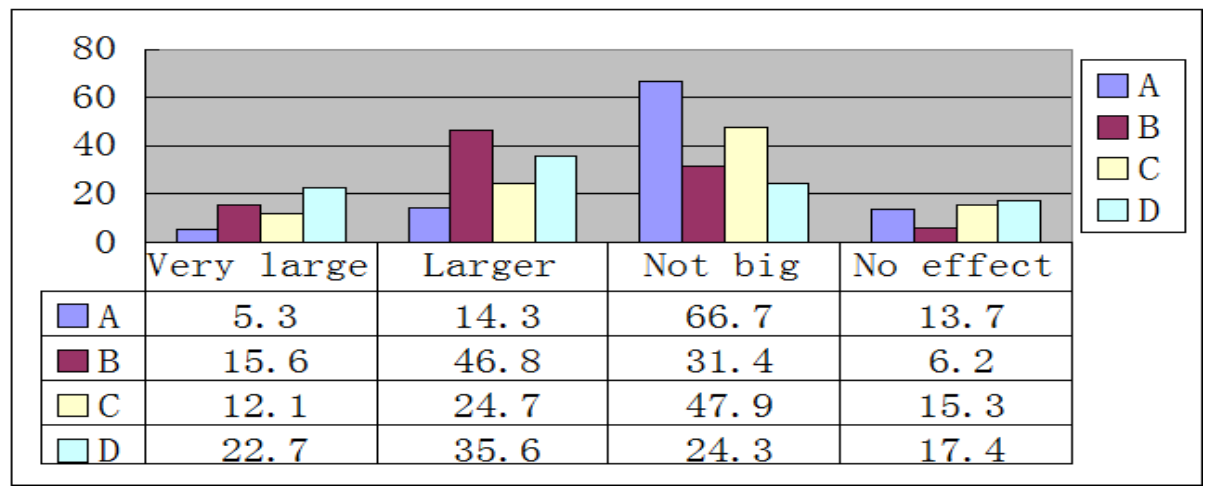

Fig. 2. The statistics of sports atmosphere in school.

\subsection{Influence of Social Factors on College Students' Selection of Leisure Sports}

Social factors that have influence on college students' selection of leisure sports include families, mass media and peers, among which, family members' attitude on sports, their sport habits and their support have direct influence on the degree of participation in leisure sports as well as on the selection of sport items. Game reports by mass media and publicity of new sport items are an important channel for students 
to know about sports. Peers of the same age also have some influence on the participation in leisure sports as well as on the selection of sport items.

Table 3. Influence of Social Factors on College Students' Selection of Leisure Sports

\begin{tabular}{|c|c|c|c|c|}
\hline Degree of influence & Very large & Large & Small & None \\
\hline Family & 24.6 & 36.7 & 20.3 & 8.4 \\
\hline Mass media & 13.5 & 47.2 & 21.5 & 18.8 \\
\hline Peer & 26.3 & 44.6 & 16.7 & 12.4 \\
\hline
\end{tabular}

Table 4. Statistics of Satisfaction with Sport Items (Unit: \%)

\begin{tabular}{|c|c|c|c|c|c|c|}
\hline \multicolumn{2}{|c|}{ Degree of satisfaction } & Very satisfied & Relatively satisfied & Satisfied & Dissatisfied & Very dissatisfied \\
\hline \multirow{2}{*}{ Boys } & Traditional items & 7.5 & 22.5 & 52.5 & 12.5 & 5 \\
\cline { 2 - 7 } & New items & 0 & 5 & 17.5 & 20 & 57.5 \\
\hline \multirow{2}{*}{ Girls } & Traditional items & 2.9 & 22.9 & 48.6 & 17.1 & 8.6 \\
\cline { 2 - 7 } & New items & 0 & 5.7 & 11.4 & 40 & 42.9 \\
\hline \multirow{2}{*}{ In total } & Traditional items & 4 & 10.7 & 46.7 & 28 & 10.7 \\
\cline { 2 - 7 } & New items & 0 & 5.3 & 14.7 & 30.7 & 49.3 \\
\hline
\end{tabular}

In the investigated social factors, families, mass media and peers have shown big influence on ordinary students' participation in leisure sports (Table 3). Seen from the overall proportion, peers of the same age have the biggest influence60.7\%, which, perhaps, is because college students are curious, open to new information and they are chasing after fashion and living together that they can exchange ideas all the time. This is similar to a previous conclusion drawn by other scholars. The investigation shows that there is no significant difference in students participating in leisure sports whose parents have different education backgrounds. Socialist modernization construction is clearly more needs to have the innovation ability, innovation ability and innovation spirit, which puts forward many new requirements on the traditional higher education and urges the need of optimization and adjustment to the existing education system.

\subsection{Analysis on Satisfaction with Sport Items Carried out in College}

To what degree will students be satisfied with the sport items carried out in a college can reflect, from one side, the tendency of students' choices of leisure sports. Some new sport items do not need field and facilities. However, some are still in need of field and facilities, such as tennis (which needs field) and taekwondo (which needs a gym). In addition, students may be dissatisfied if the new items cannot reach their expectation.

It can be seen from the above that, college students are basically satisfactory with traditional sport items $61.4 \%$, but, because most students are well-informed and are curious to novel things, the introduction and implementation of new sport items cannot reach students' expectation80\%. Further more, there is a shortage of both fields and facilities for the new sport items, which makes it difficult to carry out these items. As a result, college students are highly satisfactory with the new sport items and their fields and facilities [9].

The results show that: 1) Leisure Sports autonomy, with a time dominated by features of flexibility in the choice of activities, the purpose of entertainment and fitness activities. 2) students' knowledge on leisure sports is not deep enough, cognitive diversify; students' participate in a variety of types of leisure activities in a more ample leisure time; small proportion of the cost of living for Leisure Sports Consumption Leisure Sports Consumption structure is irrational; activities of choice due to personal circumstances, gender and other factors showing differences. 3) Traditional Sport Fitness concept is still the main purpose of the majority of students to participate in leisure sports, participation in leisure and sports activities form boys casual partners and alone, girls generally have a fixed companions; most students Participating in Leisure Activities feel relaxed, happy. 4) All surveyed many of the colleges and universities just opened casual 
just opened casual sports-related elective courses, there is no specific set Leisure Sports, school and leisure physical education is relatively backward, school sports facilities and leisure sports service is not perfect, can not meet the majority of students needs, student demand for school sports facilities and leisure sports information services [10]. Physical education ability of leisure will also constraint the development of leisure sport education the teaching course is mainly involved with martial arts, aerobics and other traditional, causing student to form a comprehensive understanding of leisure sports.

\section{Suggestions}

1) Good sport consciousness and view of sport value view, right sport attitude and habit, strong sport interest and hobby are all the inner motivation for college students to participate in leisure sports. Colleges, or universities, shall provide services for leisure sport activities, cultivate mainstay students for sports, build sound and diverse sport organizations, help students to develop their life-long sport consciousness and habit, establish long-term effective mechanism for supervising and safeguarding sport activities, and promote students to participate in necessary sport activities.

2) Colleges shall strengthen the construction and management of sport infrastructures and make full use of existing sports facilities provide convenience for students to participate in leisure sports. PE teachers shall give some free sport guidance for students to improve their sport skills. Some new sport items that do not need a field shall be especially carried out to provide students with more and better chances to take exercises.

3) PE is an important factor that has influence on college students' participation in leisure sports. Colleges shall enhance the training of PE teaching staff and offer them with chances for further education to improve their knowledge and skills related to leisure sports. Both traditional and modern sport items are applicable to be carried out in sports clubs. Active introduction of new sport items can meet students' different requirements for leisure sports. Colleges can cooperate with social sport organizations to provide students with more and better chances to participate in leisure sports.

4) Create actively a sport atmosphere and promote sports into life. Guide correctly students' consumption of leisure sports. Give more lectures about sport knowledge to heighten students' sport theories and sport consciousness. Impart the knowledge about new sport items during physical education.

5) Different demands of both boys and girls shall be paid attention to when new sport items are introduced in colleges or universities. Regular investigations shall be carried out to figure out what are the items that most students want to participate in. Meanwhile, more knowledge about new sport items shall be taught to create a new sport atmosphere where students can make friends who share the same hobbies.

6) "Education of personality development" and "vocational education for modern and future lives" shall be taken as the breakthrough point (1). In specific physical education practices and activities, diverse leisure sports shall be offered to students. Wherever possible, provide conveniences for students to have free choice of sport items, so as to arouse their enthusiasm, take their advantages on certain sport items and allow them to develop life-long sport habits.

\section{Conclusions}

Allow college students to have full understanding on the positive functions of participating leisure sports; enhance their knowledge and ability related to leisure sports; thus improve their perceived control ability to participate in leisure sports to influence their behavioral intention, and; generate actual behaviors 
of participating leisure sports. These objectives shall be realized by more physical education and publicity efforts. Therefore, policy makers shall start from the conveniences of leisure sports and put emphasis on the value of the instrumentality belief to replace the concept that compels students to participate in sports. As for self-competence, colleges shall establish a specialized consulting institution to give advice about leisure sports, train their ability of planing leisure sports for themselves, and assist students to settle the problems generated in the scenario of leisure sports, so as to improve their ability of participating in leisure sports. As for the studies on conveniences, many scholars in China reported that the shortage of sport facilities in colleges and universities and the weakness of sport ability are the important factors that set back students' participation in leisure sports. Hence, governments or colleges shall construct widely fields and facilities for leisure sports, so as to increase the chances and enhance the motivations for students to participate in leisure sports.

\section{Reference}

[1] Astin, A. W. (1984). Student involvement: A development theory for higher education. Journal of College Student Personnel, 47-49.

[2] Diener, E., Ernmons, R. A., \& Larsen, R. J. (1992). The satisfaction with life scale. Journal of Personality Assessment, 71-75.

[3] Danell J. H. (2006). The perceived barriers to research in college recreational sports. Journal of Recreational Sports, 69-71.

[4] James, F. W. (1998). A comparison of traditional and non-traditional students' leisure attitudes and leisure motivations. Journal of Recreational Sports, 87-90.

[5] Bill, S., \& Hsiao-Chun, L. (1998). Recreation students' attitude toward intramural sports. Journal of Recreational Sports, 56-59.

[6] Philip, A. (1999). Theodore. Promoting moral growth through campus recreation. Journal of Recreational Sports, 66-68.

[7] Michael, A. K. (2000). Recreational sport participation as a moderator of college stress. Journal of Recreational Sports, 48-52.

[8] Sarah, J. Y., \& Craig, M. R. (2000). Recreational sports trends for the 21century: Results of a Delphi study. Journal of Recreational Sports, 32-35.

[9] Danell, J. H. (2000). Undergraduate student benefits from university recreation. Journal of Recreational Sports, 77-81.

[10] Mike, V., \& Jeff, K. (2000). Monitoring and promoting good sportsmanship as an essential element of intramural sports. Journal of Recreational Sports, 33-36.
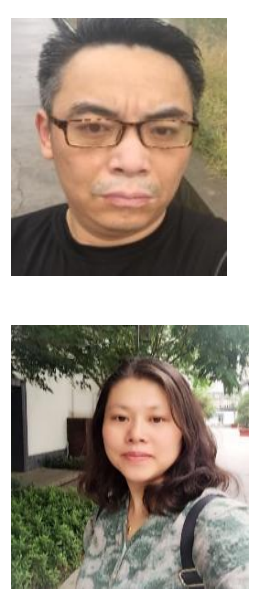

Jian-Qiang Guo wan born in September 1972, Yixing, Jiangsu province. He is an associate professor. His research interests are mainly engaged in leisure sports teaching and research.

Xian Liu wan born in January 1980, Changzhou, Jiangsu province. She is a lecturer. Her research interests are mainly engaged in leisure sports teaching and research. 